\title{
The Role of the Blue Ocean Strategy in Achieving a Competitive Advantage: An Empirical Study on Al - Rajhi Bank - KSA
}

\author{
HANY ALY SHARED \\ Business Department, College of Science and Humanities, Shaqar University - KSA \\ E-mail: hshared@su.edu.sa, hshared@gmail.com
}

\begin{abstract}
The aim of this research is to identify the extent to which the banking sector in Saudi Arabia has adopted the strategy of the Blue Ocean in enhancing competitive advantage. The study measured the effect of the blue ocean strategy dimensions (Eliminate, Reduce, Raise, Create) on competitive advantage. The research collected 96 surveys from employees from Al Rajhi Bank in Riyadh. The results of the factor analysis showed that the strategy of the Blue Ocean affects competitive advantage. The regression analysis also showed a significant correlation between the dimensions of the Blue Ocean strategy and competitive advantage.

Keywords: Blue Ocean Strategy, Competitive Advantage, Al - Rajhi Bank, Eliminate, Reduce, Raise, Create.
\end{abstract}

\section{Introduction}

The rapid and continuous growth in business is one of the most important features of the present era. The opening of most of the world markets to each other has become a real reality among countries. Contemporary business organizations are suffering from the competition, changing customer patterns, and strong supply from strong demand. It is, therefore, necessary for organizations to adopt new strategies to ensure their survival, excellence and market leadership.

Blue Ocean Strategy is the development of the strategic management concept in the evolving and changing world of business. This strategy shows that leading companies do not excel in battles and conflicts with competitors, but rather by finding "blue oceans" in new markets that have not reached the depths of their predicament through "value innovation" that delivers strong leaps in values for both the organization and the client. The blue ocean strategy also means creativity and innovation in products and services in the face of fierce competition in the business world.

The economy of the Kingdom of Saudi Arabia is witnessing a state of contraction during 2017 at a rate of $0.74 \%$, with the gross domestic product at constant prices to reach 2.568 billion riyals ( $\$ 684.8$ billion). The decline in GDP was due to the decline of the oil sector, which contracted by $2.97 \%$ to reach 1.104 billion riyals ( $\$ 294.4$ billion).

Saudi Arabia's financial markets witnessed multiple fluctuations during 2017, largely influenced by the global and local economic conditions surrounding the region, including the political situation in the region and structural reforms taking place in the local economy. The blue ocean strategy ensures a strategy for any 
organization within this sector, excellence, and leadership from the rest of the competitors in the long term, by creating a new product or increasing its market share.

\section{Literature Review}

\section{Blue Ocean Strategy}

Organizations face many challenges in order to survive and maintain their market share, in light of conflicts and clashes with competitors. Organizations can choose between different strategies that suit the circumstances of each organization. Some of them focus on product, price, promotion or through distribution methods that cover the targeted parts of the market. This is what all organizations seek to assess their ability to create new value for the product by following a new strategy (Kim \& Mauborgne, 2005).

As competition intensifies, companies focus on price competition at the expense of product quality. In order to avoid conflicts with competitors and help to increase profits and minimize simulations (Dennis, 2009), companies seek to find a comparative advantage over competitors in the market through a quantum leap in product value, But companies cannot maintain this advantage in the long run because of corporate simulations of this feature (Burke, et al., 2009).

Therefore, companies rely on a strategy of protection inspired by military science through confrontation and defence of the company's interests in the market (Dehkordi, et al., 2012). The result of these increases is an increase in the profits of a company at the expense of another company that achieves losses and withdraws from the market (Burke, et al., 2009). Despite the importance of competition for companies, but the focus on competition, the company loses many aspects, including interest in finding innovative value of the product in new places in the market, has not been exploited before, and there is no competition and this is applied to the strategy of the Blue Ocean (Buisson \& Silberzahn, 2010).

The Blue Ocean strategy is a term of modern terminology in administrative literature during the $21 \mathrm{st}$ century. But the concept of this strategy is not new, as there are many companies before the term, it had the leadership and excellence through which to create a new value for the product, which was able to open new markets did not exist before and far from competition and collide with competitors such as Ford, Dell (Čirjevskis, et al., 2011).

Kim and Mauborgne (2015) indicated that The Blue Oceans is industries and markets that have not yet been identified as non-existent and are entirely new markets with the potential to generate profitable and attractive returns. On this basis, the strategy of the Blue Ocean represents the means to detect the locations of markets that have not reached the competition.

Kotler believes that the Blue Ocean is how to bypass the organization's current market boundaries and seek to find new markets for its existing products, leaving the competition in the back (Kotler, 2008). Companies can follow the Blue Ocean strategy to avoid competition by developing products or covering parts of the market that have not been covered before.

Such as Starbuck's, which developed a coffee drink with many flavours that influenced the spread of fast coffee worldwide, having been drinking indoors only, has transformed the company coffee drinks into entertainment and fun (Dennis, 2009).

Kim and Mauborgne (2005) point out that there are six principles by which companies can make effective industry or market policy changes to implement the Blue Ocean Strategy: 
Principle 1: Restructuring Market Boundaries

This principle is to redefine the market boundaries out of competition and addresses the risks faced by companies to determine the strategy that the company will implement through six tracks (Kim \& Mauborgne, 2005);

- Follow-up similar organizations and try to be the best within it

- Follow-up industries by focusing on strategic groups such as cars (luxury - economic - family).

- Focus on the desires and needs of the consumer group.

- Identify the range of products and services in similar industries.

- Approval of the career and emotional orientation of the sector.

- $\quad$ Track time changes and competitive threats.

Principle 2: Focus on the Big Picture, Not the Numbers.

This means that companies focus on the full picture of current industry conditions and the existing competitive situation, rather than focusing on figures and operational data that may lead to the loss of the company's main objective between the large numbers and data. Managers must develop a corporate image by thinking out of the box out of competition and exploring opportunities (Kim \& Mauborgne, 2005).

\section{Principle 3: Reach Beyond Existing Demand}

This principle focuses on how to maximize the size of the blue ocean that has been created, thinking about products that meet the desires and needs of potential customers, to attract new customers who have not existed before. With a focus on differences in consumer needs through more precise market specialization and segmentation, to reach beyond current demand (Kim \& Mauborgne, 2005).

Principle 4: Get the Strategic Sequence Right

After exploring the blue ocean potential, identify the target consumers sector. The organization must implement the strategies that have been identified in the right order to reach customer expectations and reduce potential risks (Kim \& Mauborgne, 2005). According to the following figure:

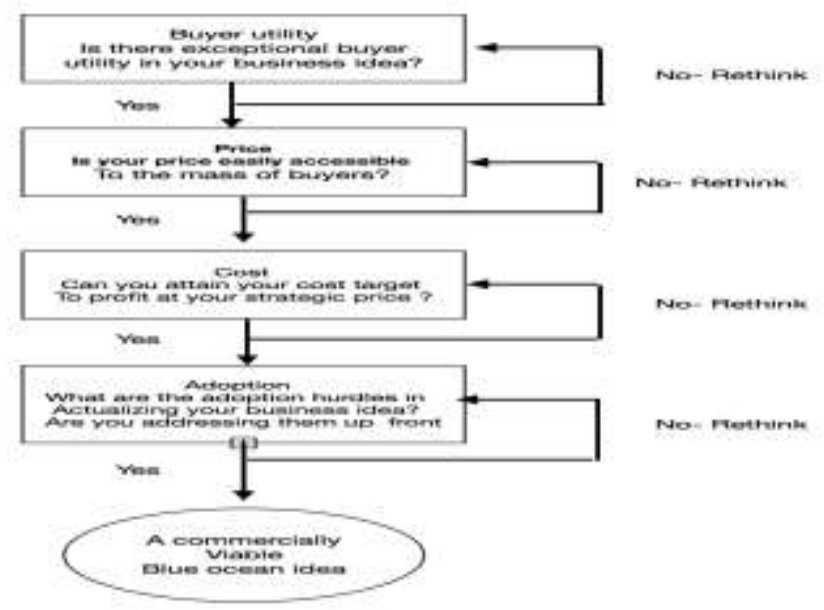

Figure 1: The Sequence of Blue Ocean Strategy

Source: Kim \& Mauborgne, 2005,P.118. 
Principle 5: Overcome Key Organizational Hurdles:

New strategies often face many organizational obstacles to their implementation. Therefore, the administration must resolve internal divisions and avoid potential conflicts in order to ensure that employees support the transitional period in the life of the organization (Kim \& Mauborgne, 2005). Organizational obstacles to the organization are moral obstacles, lack of motivation among teams, limited resources and resistance to influential people. According to the following figure:

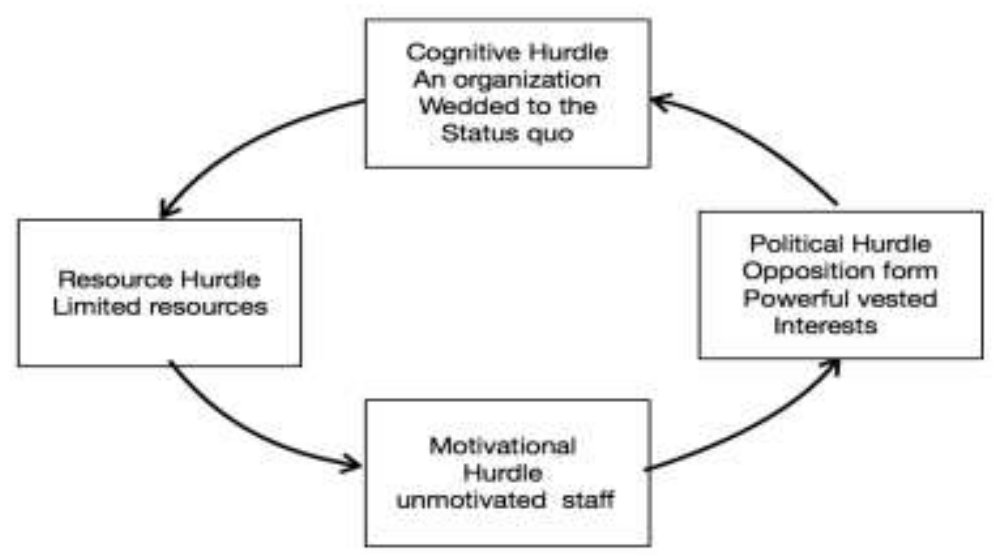

Figure 2: The Four Organizational Hurdles to Strategy Execution Source: Kim \& Mauborgne, 2005, P.150.

Principle 6: Build Execution into Strategy:

The implementation and building of the strategy depend not only on the senior management but also on the middle management and all the employees of the organization. In order for the organization to overcome the obstacles that it faces and achieve the desired goals, it is necessary to identify the attitudes and behaviour of the employees and to build a culture of trust and commitment that motivates the employees to implement the agreed strategy (Kim \& Mauborgne, 200).

\section{Dimensions of Blue Ocean Strategy:-}

Kim and Mauborgne (2005) indicate that four key measures to build a new product value in the form of questions to reduce red ocean strategies:

- What elements should be removed from the industry, that takes for granted?

- Which elements should be reduced to the lowest level in the industry?

- What elements should be increased from the industry standard?

- What elements should be found and not made in the industry before?

Many researchers; Choyt (2007) Saxtoft (2008), Siegemund (2009), and Yang (2007) concurred with Kim and Mauborgne (2005) on the dimensions of the blue ocean Strategy (Eliminate, Reduce, Raise rand Create)

The following figure (3) illustrates the dimensions of the blue ocean Strategy: 


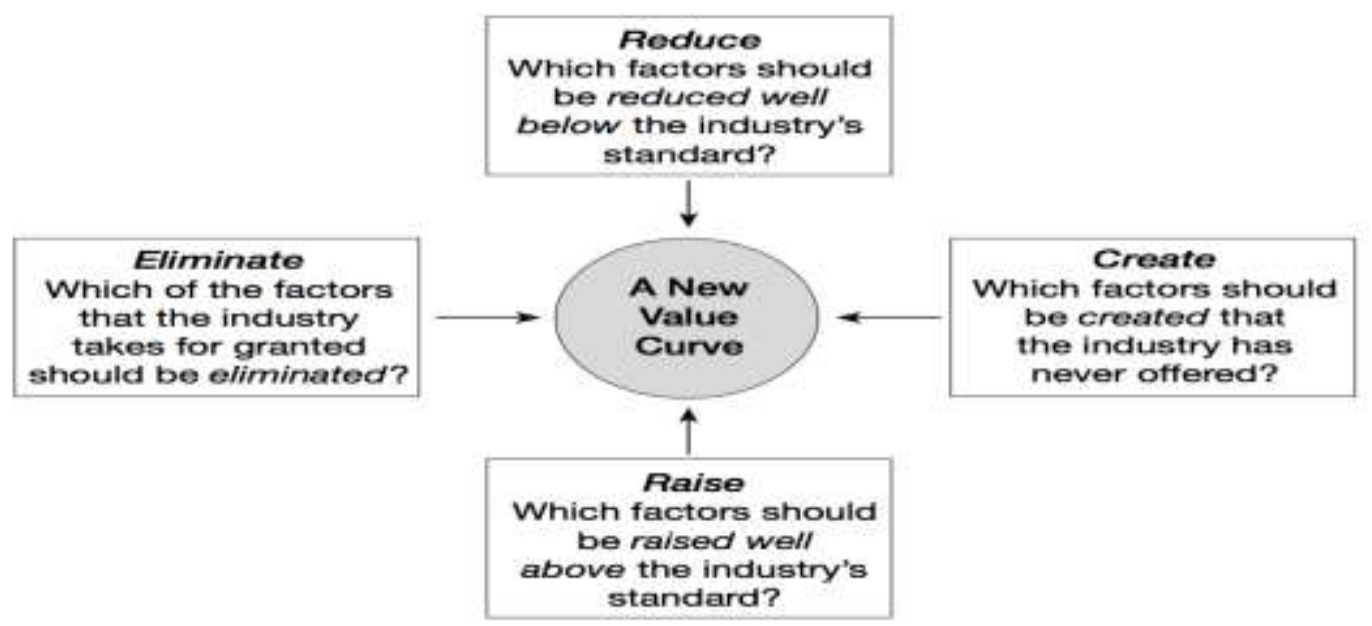

Figure 3: The Four dimensions of the blue ocean Strategy.

Source: Kim \& Mauborgne, 2005, P.29.

The following is a brief explanation of each of these dimensions, which will be the cornerstone in the adoption and creation of the blue ocean strategy:

\section{Eliminate:}

It means the removal or exclusion of unnecessary elements that do not affect the levels of sale or quality. This affects the reduction of costs to the minimum possible, so the organization should reconsider some of the useless operations that do not provide any benefit to the organization or serve the work or production processes while maintaining the same volume of sales and costs. Such as cancelling one of the branches that are not economically viable for the organization's activity, or excluding the unregulated and expensive employees, as eliminating them reduces wage costs and achieves the organization's excellence from its competitors.

\section{2- Reduce:}

It means reducing some of the measures that the organization deems unnecessary at work, which in turn reduces costs unnecessarily. This contributes to the reduction of the total costs that directly affect the increase in profits realized. Such as old procedures and ideas that are useless or impossible to implement or reduce harmful applications to the environment in order to distinguish the organization against its competitors.

\section{3-Raising:}

It is intended to add some elements that will increase the capacity of the organization and improve the quality to achieve the wishes and needs of the consumer. Such as increasing sales, increasing product promotions, expanding customer service and loyalty programs. This affects the organization's rapid growth and achieving excellence from its competitors.

\section{Creation:}

It is intended to transform creative ideas into useful products that serve the desires and needs of consumers, and therefore organizations that have the ability to transform innovative ideas into useful products are the best and distinct organizations from the rest of the competitors. Such as finding a new value for the product 
or discovering new areas in the market that have not been exploited before. This affects the organization's activity and its ability to find a Competitive advantage through which it can distinguish from competitors.

\section{Competitive Advantage}

Competitive advantage is a controversial issue among academics and managers, as each of them uses a different concept in many different contexts (O'Shannassy, 2008). The concept of competitive advantage has been of interest to researchers for several decades. Ansoff (1965) defined it as the special characteristics of the organization, which gives it a strong competitive position in the market, as Porter (1985) defined it as the ability of the organization to create additional value for the product (Christos, 2015,).

Sigalas et al. (2013) identified two pathways for defining competitive advantage: first in terms of performance, such as the organization's high profits and outstanding financial performance, and the second track in terms of the source of competitive advantage such as product characteristics and location (Sigalas \& Pekka-Economou, 2013).

Ranjith (2016) believes that competitive advantage is a strategy based on the development of the company's business model, driving the growth and development of the company, and providing the company with the opportunity to produce and deliver services, goods, and benefits to customers that surpass its competitors in the market, achieve more profits and improve its reputation in the market (Ranjith, 2016).

Some administrative literature has identified the dimensions of competitive advantage (quality of products and services, innovation, flexibility, the cost and responsiveness to customers) as key to achieving the competitive advantage of organizations (Charles, et al., 2009; Hill \& Jones, 1989 ; Sachitra, et. al., 2016 ; Janakova \& Zatrochova, 2015 ).

\section{Al - Rajhi Bank - KSA}

The Central Bank of the Kingdom of Saudi Arabia (SAMA), was established in 1952 to carry out the work of the Government Bank. And the supervisor on commercial banks, insurance companies, finance companies, money exchange offices, and credit information companies (SAMA, 2019). Al Rajhi Bank, one of the largest Islamic banks in the world, was established in 1957. In 1978, the merger of the various institutions under the name Al Rajhi under one umbrella in Al Rajhi Banking and Trading Company. In 1988, the Bank was transformed into a Saudi joint stock company.

Al Rajhi Bank is one of the largest banking and investment companies with a Saudi capital of (SR 16.25 billion) ( $\$ 4.3$ billion). It manages assets worth (SR 343 billion) (\$90 billion) and has more than 10,200 employees.

The bank has the largest branch network in the Kingdom (more than 570 branches, 233 transfer centres, and 152 women's branches), the largest network of ATMs (over 4,794) Of 74,612 points of sale and 233 remittance centres, and has the largest customer base among Saudi banks. The Bank has international branches in Malaysia, Kuwait, and Jordan (Alrajhibank, 2019).

\section{Research Framework}

Based on previous literature, this study presents a framework for research that links the dimensions of the Blue Ocean strategy with the competitive advantage as shown in Figure (4). In this framework, the blue ocean strategy consists of four dimensions: Eliminate, Reduce, Raise, and Create (Kim \& Mauborgne, 2005). 


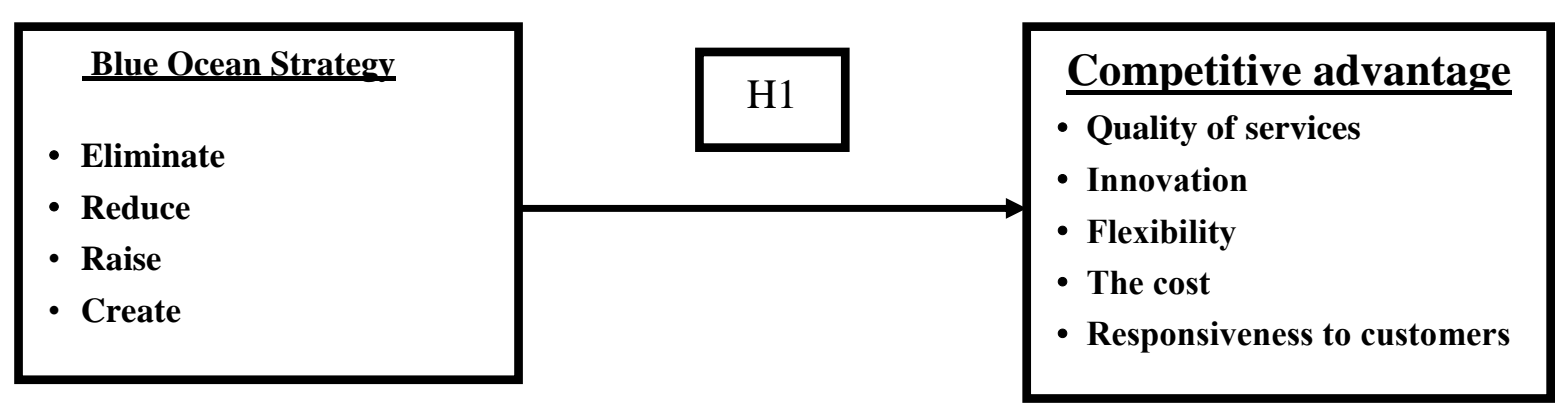

Figure 4: framework of Blue Ocean strategy and competitive advantage.

\section{Hypothesis}

There is not much research on the impact of the blue ocean strategy on the competitive advantage in Rajhi Bank - KSA, we propose the following hypothesis:

H1. the Blue Ocean strategy has a positive effect on the competitive advantage.

H1.1 Eliminate has a positive effect on the competitive advantage.

H1.2 Reduce has a positive effect on the competitive advantage.

H1.3 Raise has a positive effect on the competitive advantage.

H1.4 Create has a positive effect on the competitive advantage.

Questionnaire Development and Sampling

In this study, the survey questionnaire was designed to survey employees at the branches of Al-Rajhi Bank to demonstrate the impact of the Blue Ocean strategy to achieving competitive advantage. Through previous studies, the dimensions of the blue ocean strategy that affect competitive advantage have been determined. The survey was conducted at Al-Rajhi Bank branches in Riyadh between December 2018 and January 2019, the sample was randomly selected 140 questionnaires were distributed, of which 96 were validated. A questionnaire was distributed in Arabic through interviews. A questionnaire list contains 28 variables arranged in two sections according to the following:

(1) The Blue Ocean strategy dimensions (Q1-11).

(2) The competitive advantage (Q12-28).

\section{Analysis and Results}

In order to study the effect of the Blue Ocean on the competitive advantage of Al-Rajhi Bank, we use a variety of procedures in this section.

\section{Reliability Analysis}

In order to determine the reliability of the variables under study, we used Cronbach's alpha reliability test that expresses the reliability of multiple element scales. However, this measure is employed for various Likert-type elements that are gathered in order to make summated scale (following Leech et al. 2005: 67, the value of Cronbach's alpha should exceed 0.5 ). In this analysis, the questionnaire contains 28 questions. Table (1) presents the results of the reliability test. 
Table 1: The results of the reliability analysis to dimensions of the Blue Ocean strategy and competitive

\begin{tabular}{|ccc|}
\hline \multicolumn{1}{c}{ advantage. } & \\
\hline Variables & Items & Cronbach's alpha \\
\hline Eliminate & 3 & 0.625 \\
Reduce & 2 & 0.652 \\
Raise & 2 & 0.623 \\
Create & 4 & 0.736 \\
Overall & 11 & 0.813 \\
quality of services & 4 & 0.725 \\
innovation & 4 & 0.632 \\
flexibility & 3 & 0.823 \\
the cost & 3 & 0.655 \\
responsiveness to customers & 3 & 0.673 \\
Overall & 17 & 0.845 \\
\hline
\end{tabular}

The estimates values of Cronbach's alpha for all the variables and for the overall questionnaire are in a good range. In fact, the estimated value of this coefficient for the Blue Ocean strategy is 0.813 , and competitive advantage is 0.845 . Suggesting that our variables and the instrument are reliable. In addition, our results based on the reliability tests confirm that for any further question the data and the instrument are reliable.

\section{Structure Validity}

Structural validity is one measure of the validity of a tool that measures the extent to which the objectives of the tool are achieved. It shows the extent to which each field of study is closely related to the questionnaires. Table (2) shows that all correlation coefficients in all areas of the questionnaire are statistically significant at $\alpha<0,05$.

Table 2: Results of Coefficient of correlation to dimensions the study.

\begin{tabular}{|lcc|}
\hline Variables & $\begin{array}{c}\text { Spearmen } \\
\text { Correlation }\end{array}$ & Sig. \\
\hline Eliminate & 0873 & 0.000 \\
Reduce & 0.822 & 0.000 \\
Raise & 0.843 & 0.000 \\
Create & 0.856 & 0.000 \\
Overall & 0.912 & 0.000 \\
quality of services & 0.725 & 0.000 \\
innovation & 0.532 & 0.000 \\
flexibility & 0.824 & 0.000 \\
the cost & 0.756 & 0.000 \\
responsiveness to customers & 0.677 & 0.000 \\
Overall & 0.943 & 0.000 \\
\hline
\end{tabular}

\section{Kaiser-Meyer-Olkin and Bartlett's tests of sampling adequacy}

To check the sufficiency of our sample we employ the Kaiser-Meyer-Olkin (KMO) and Bartlett's tests. The KMO test is a measure that can be used to examine whether each factor has suitable items for producing a proper group. However, the estimated value of the KMO test should be greater than 0.5. Insufficiency in factors can exist for values of KMO test less than 0.5 (Leech et al. 2005: 82). Bartlett's test is utilized to determine whether the correlation matrix across factors has significantly different properties than an identity matrix. The probability value of Bartlett's test is compared to the 0.05 level. So, values less than 0.05 indicating the existence of different properties of the correlation matrix versus the identity matrix. 
Study displays the results of KMO and Bartlett's tests in Table (3).

As shown by the results of KMO test the items within each factor are sufficient and demonstrate an adequate item for making groups. The estimated values are greater than 0.86 . The significance value of Bartlett's test is 0.000 which is less than 0.05 . This result suggests an adequacy correlation between variables, which confirms a factor analysis.

Table 3: Results of KMO and Bartlett's test
KMO measure of sampling adequacy
0,861
Bartlett's test of sphericity
Approximate chi-square.
6.513 .239
The Degree of freedom
Probability
0.000

\section{Total variance explained}

In this subsection, we use the total variance explained method that explains how the variance may be divided via the potential variables. The Eigenvalue criterion which measures the variance explained is used to show the usefulness of a factor. However, the calculated values should be more than 1.0. Values less than 1.0 indicate that a factor explains less information than the individual item would have described. We report in Table (4) the results of the total variance explained.

From the results of the total variance explained presented in Table (4) one may note that the cumulative variance explained by the factors is about $84 \%$. This result indicates that a very good percentage of the variance may be elucidated by the considering factors.

Table 4: Results of variance explained

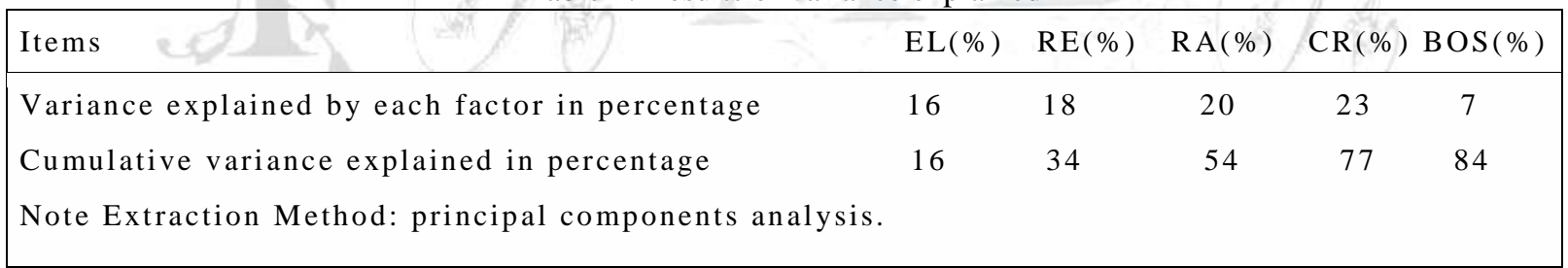

\section{Spearmen Correlation Matrix:}

To determine the power and the direction of the linkage between factors the correlation coefficients of Spearman were applied. The estimated coefficients are shown as following Table (5). The following results were obtained as shown in the following table:

Table 5: Spearman Correlation Matrix.

\begin{tabular}{|c|c|c|c|c|c|c|c|c|c|c|c|}
\hline Variables & EL & $\mathrm{RE}$ & $\mathrm{RA}$ & $\mathrm{CR}$ & $\mathrm{BO}$ & QU & IN & FL & $\mathrm{CO}$ & $\mathrm{RE}$ & $\mathrm{CA}$ \\
\hline Eliminate & 1 & & & & & & & & & & \\
\hline Reduce & 0.754 & 1 & & & & & & & & & \\
\hline Raise & 0.677 & 0.675 & 1 & & & & & & & & \\
\hline Create & 0.649 & 0.619 & 0.643 & 1 & & & & & & & \\
\hline Blue Ocean & 0.877 & 0.876 & 0.867 & 0.853 & 1 & & & & & & \\
\hline $\begin{array}{l}\text { quality of } \\
\text { services }\end{array}$ & 0.573 & 0.695 & 0.698 & 0.543 & $\begin{array}{l}0.71 \\
6\end{array}$ & 1 & & & & & \\
\hline
\end{tabular}




\begin{tabular}{|lccccccccccc|}
\hline innovation & 0.665 & 0.786 & 0.697 & 0.659 & 0.76 & 0.71 & 1 & & & \\
flexibility & 0.687 & 0.733 & 0.726 & 0.698 & 0.76 & 0.69 & 0.78 & 1 & & \\
& & & & & 7 & 5 & 8 & & & \\
the cost & 0.567 & 0.653 & 0.588 & 0.742 & 0.59 & 0.70 & 0.65 & 0.59 & 1 & \\
responsiven & 0.061 & 0.685 & 0.735 & 0.632 & 0.67 & 0.74 & 0.74 & 0.57 & 0.69 & 1 \\
$\begin{array}{l}\text { ess to } \\
\text { customers }\end{array}$ & 1 & & & & 5 & 3 & 2 & 8 & 0 & \\
$\begin{array}{l}\text { competitive } \\
\text { advantage }\end{array}$ & 0.736 & 0.819 & 0.905 & 0.667 & 0.78 & 0.86 & 0.76 & 0.64 & 0.76 & 0.68 & 1 \\
& & & & & 5 & 5 & 6 & 5 & 8 & 8 \\
\hline
\end{tabular}

The results of the Spearman correlation matrix indicate a significant positive relationship between competitive advantage (considered as the dependent variable) and the Blue Ocean strategy defined by Eliminate, Reduce, Raise and Create (considered as the independent variables) at $1 \%$ significance level.

\section{Regression Analysis}

This subsection illustrates the results of regression analysis, as presented in Table (6). We notice that all dimensions of Blue Ocean present a significant positive effect on the competitive advantage. We also remark that Raise has the highest coefficient (0.321) compared to all other dimensions.

This result indicates that competitive advantage is highly dependent on Raise. Our results also show that the second most effective factor of competitive advantage is Create, as indicated by its correspondent coefficient 0.276. In addition to that, we show that Eliminate variable presents the lowest effect on competitive advantage.

Table 6: Results of regression analysis.

\begin{tabular}{|lccc|}
\hline Variables & Coefficient & t-statistics & Sig. \\
\hline Eliminate & 0.178 & 4.567 & 0.038 \\
Reduce & 0.188 & 2.308 & 0.027 \\
Raise & 0.321 & 4.986 & 0.001 \\
Create & 0.276 & 2.927 & 0.005 \\
Adjusted R & & 0.655 & \\
& & & \\
F-statistics (Probability) & & $80.178(0.000)$ & \\
Sig. 0.000 & & & \\
\hline
\end{tabular}

\section{Conclusion}

This research firstly aims to investigate the relationship between dimensions of Blue Ocean strategy (Eliminate, Reduce, Raise and Create) and competitive advantage in Al - Rajhi Bank - KSA. Secondly, our objective is to identify The Blue Ocean strategy the factors that have a significant effect on competitive advantage.

To do that we adopt a survey research questionnaire consist of 28 items for collecting data from the employees at the branches of Al-Rajhi Bank. Our sample consists of 96 respondents. The data were analyzed by some statistical methods, such as the Cronbach's alpha, Kaiser-Meyer-Olkin, Bartlett's test, and regression analysis. 
Our results show that The Blue Ocean strategy is prominent for competitive advantage. We found that four factors of Blue Ocean strategy have a significant impact on competitive advantage, namely, Eliminate, Reduce, Raise and Create.

\section{Our Research Recommends the Following:}

Banks in KSA should endeavour to take care of innovative ideas for pursuing technological development and setting up financial services to meet customer desires and serve the national economy And Encourage employees to provide creative ideas that contribute to the Bank's competitive advantage.

Saudi Banks should Look for an innovative way to measure customer satisfaction (both internal and external) to the benefit of their loyalty to the bank.

Emphasis on the increased index and its role in developing the quality of services and continuous improvement of the presentation method.

Adhering to the downsizing principle that helps the bank reduce service delivery errors to improve the quality of services provided.

Emphasize the principle of eliminating by eliminating the systems and procedures that lead to the length of service provision, as well as the Elimination of people who are not well qualified, which contributes to reduce costs and increase the growth of the bank and revenue.

\section{References}

Buisson, B. \& P. Silberzahn (2010). Blue Ocean Or Fast-Second Innovation? A Four- Breakthrough Model To Explain Successful Market Domination. International Journal of Innovation Management (ijim),14(03), 359-378. https://doi.org/10.1142/s1363919610002684

Burke, A. E., A. Van Stel (2009). Blue Ocean versus Competitive Strategy: Theory and Evidence. ERIM report series research in management Erasmus Research Institute of Management. Erasmus Research Institute of Management. Retrieved from http://hdl.handle.net/1765/16037

Charles W.L. Hill \& Gareth RJones, (2009). Essentials of Strategic Management.Boston: South Western.

Choyt, Marc. (2007). My Application of Blue Ocean Strategy to Jewlery. Fair Trade Jewlery.

Christos Sigalas, (2015) .Competitive advantage: The known unknown concept. Management Decision, 53 ( 9), 2004-2016. https://doi.org/10.1108/MD-05-2015-0185

Čirjevskis, A., Homenko, G.,\& Lačinova, V. (2011). How to implement Blue Ocean Strategy (BOS) in B2B sector. Business, Management and Education, 9 (2), 201-215. http://dx.doi.org/10.3846/bme.2011.14

Dehkordi, G.J., Rezvani, S. ,\& Behravan , N. (2012). Blue Ocean Strategy: A Study Over A Strategy Which Help The Firm To Survive From Competitive Environment. International Journal of Academic Research in Business and Social Sciences, 2(6).

Dennis Pitta, (2009).Issues in a down economy: blue oceans and new product development. Journal of Product \& Brand Management, 18 (4), 292 - 296. http://dx.doi.org/10.1108/10610420910972819

Hill, C. W. \& Jones, G. R., (1989). Strategic management an integrated approach. (4th ed.), New York: Houghton Mifflin co.

Janakova, H. \& Zatrochova, M. (2015). Creative Management and Innovation in Europe Automotive Dimension. European Scientific Journal, 1, 91-99.

Kim, C., \& Mauborgne, R. (2005). Blue Ocean strategy : How to create uncontested market space and make the competition irrelevant. Harvard business school Publishing Corporation, printed in the U.S.A.

Kim, C., \& Mauborgne, R. (2015). Blue Ocean Strategy, Boston. Massachusetts: Harvard Business school Pres.

Kotler, P. ( 2008) . Principles of Marketing. 12th ed. , Pearson prentice- Hall , U.S.A. 
Leech, N.L., Barrett, K.C. \& Morgan, G.A. (2005). SPSS for intermediate statistics: use and interpretation. Lawrence Erlbaum Associates, Publishers, London, available at :http://tip.iums.ac.ir/uploads/35_329_26_2.pdf

O'Shannassy, T. (2008).Sustainable competitive advantage or temporary competitive advantage: improving understanding of an important strategy construct. Journal of Strategy and Management, 1( 2), 168-180. https://doi.org/10.1108/17554250810926357

Ranjith, V. (2016). Business Models and Competitive Advantage. Procedia Economics and Finance, 37 : 203-207. https://doi.org/10.1016/s2212-5671(16)30114-9

Sachitra, V., Chong, S.C., \& Khin, A.A. (2016). Sources of Competitive Advantage Measurement in the Minor Export Crop Sector in Sri Lanka Result from Pilot Study. Asian Journal of Agricultural Extension, Economics \& Sociology, 12 (2), 1-15. https://doi.org/10.9734/ajaees/2016/27814

Saudi Arabian Monetary Authority, http://www.sama.gov.sa/ar-sa

Saxtoft, Christian. (2008). User Expectations, Communication Enablers and Business Opportunities. 3ed, Prentice Hall, John Willey and Sons.

Siegmened, Carsten. (2009). Blue Ocean Strategy for Small and Midsized Companies in German. BodBooks on Demand.

Sigalas, C. \& Pekka-Economou, V. (2013). Revisiting the concept of competitive advantage: problems and fallacies arising from its conceptualization. Journal of Strategy and Management, 6 (1), 61-80. 